\title{
Survival of women with breast cancer in central and northern Denmark, 1998-2009
}

This article was published in the following Dove Press journal:

Clinical Epidemiology

19 July 2011

Number of times this article has been viewed

\section{Lone Winther Lietzen' \\ Gitte Vrelits Sørensen' \\ Anne Gulbech Ording' \\ Jens Peter Garne ${ }^{2}$ \\ Peer Christiansen ${ }^{3}$ \\ Mette Nørgaard' \\ Jacob Jacobsen'}

'Department of Clinical Epidemiology, ${ }^{2}$ Department of Breast Surgery,

Aalborg Hospital, ${ }^{3}$ Breast and

Endocrine Section, Department of

Surgery P, Aarhus University Hospital,

Denmark
Correspondence: Lone Winther Lietzen Department of Clinical Epidemiology, Aarhus University Hospital, Aarhus Sygehus, Olof Palmes Allé 43-45,

8200 Aarhus, Denmark

Tel +4589424800

Fax +458942480 I

Email Iwl@dce.au.dk
Objective: Breast cancer is the most common cancer among women worldwide. The Nordic countries have relatively high survival, but Denmark has a lower survival than neighboring countries. A breast cancer screening program was introduced in 2007 and 2008 in the northern and central regions of Denmark respectively. We aimed to examine possible changes in survival of Danish breast cancer patients in central and northern Denmark in the period 1998-2009.

Materials and methods: From the northern and central Denmark regions, we included all women $(n=13,756)$ with an incident diagnosis of breast cancer, as recorded in the Danish National Registry of Patients during the period January 1, 1998 through December 31, 2009. We calculated age-stratified survival and used Cox proportional hazard regression to estimate mortality rate ratios (MRRs) for all breast cancer patients.

Results: Median age was 62 years (21-102 years). The overall 1-year survival improved steadily over the period from $90.9 \%$ in $1998-2000$ to $94.4 \%$ in $2007-2009$, corresponding to a 1 -year age adjusted MRR of 0.68 in 2007-2009 compared with the reference period 1998-2000. We estimated the 5-year survival to improve from $70.0 \%$ in $1998-2000$ to $74.7 \%$ in $2007-2009$, corresponding to a 5-year age adjusted MRR of 0.82 in 2007-2009 compared with the reference period 1998-2000. For middle-aged women (50-74 years) 1-year survival increased from $92.8 \%$ in $1998-2000$ to $96.6 \%$ in $2008-2009$, and 5-year survival was expected to increase from $73.9 \%$ in $1998-2000$ to $80.2 \%$ in $2007-2009$. Among younger women ( $15-49$ years) and elderly women ( $>75$ years), 1-year survival and 5-year predicted survival did not change over the two time periods.

Conclusion: Survival of breast cancer patients has improved in Denmark over the period 1998-2009, and this change was most distinct in women aged 50-74 years. Survival improved even before the implementation of a formal breast cancer screening program.

Keywords: breast neoplasm, mortality, epidemiology, population-based

\section{Introduction}

Breast cancer accounts for a substantial proportion of the cancer burden in women, with an estimated 1.4 million new cases per year and more than 450,000 breast cancer-related deaths per year worldwide. ${ }^{1}$ In Denmark, breast cancer accounted for $29 \%$ of all incident cancers and $16 \%$ of all cancer deaths among women in the period 1999-2003. ${ }^{1}$

Despite increasing survival in the Nordic countries, Denmark still has a deficit compared with the other Nordic countries. In 2005-2007, Denmark had a 3.0\% lower 1-year and $6.1 \%$ lower 5-year survival than Sweden. ${ }^{2-4}$ Prompted by the general lower cancer survival in Denmark compared with neighboring countries, National Cancer Plans 5 
were introduced in 2002 and 2005, respectively, aiming to improve survival of cancer patients. ${ }^{6}$

Breast cancer treatment in Denmark is standardized in programs formed by the Danish Breast Cancer Cooperative Group (DBCG). These programs have changed over the last decade towards a more widespread use of sentinel node technique and breast conserving surgery with adjuvant radiotherapy, ${ }^{7}$ prolonged use of tamoxifen, and introduction of aromatase inhibitors. ${ }^{8}$ Use of chemotherapy has improved with anthracyclines and/or taxanes, and most recently, in 2006, anti-HER2-therapy with trastuzumab according to the biomarker profile has been added to the programs. ${ }^{8,9}$ The beneficial effect of these treatments on survival has been documented in randomized controlled trials, ${ }^{10,11}$ and data from the DBCG database have, during the period 1977-2006, shown an increase in 5-year survival in Danish breast cancer patients from $65 \%$ to $81 \% .^{12}$

A breast cancer mammographic screening program was introduced in 2007 and 2008 in the northern and central regions of Denmark, respectively and may influence survival. Numerous investigations have proven a 25\%-30\% increased survival after introduction of screening programs in other countries. ${ }^{13-15}$

We used population-based registries in northern and central Denmark to examine changes in the mortality and survival of breast cancer patients of all ages between 1998 and 2009.

\section{Material and methods}

We conducted this study in the central and the northern Denmark regions, with a total population of 1.8 million persons. The National Health Service provides tax-supported health care for all inhabitants of Denmark, guaranteeing free treatment in hospitals. Virtually no breast cancer patients were treated in private hospitals during the study period. ${ }^{16}$

\section{Identification of breast cancer patients}

Through the Danish National Registry of Patients (DNRP), we identified all women resident in the northern or central regions of Denmark who had their first breast cancer diagnosis recorded in a hospital within one of the two regions over the period January 1, 1998 through December 31, 2009. The DNRP contains information about all admissions from nonpsychiatric hospitals in Denmark since 1977 and outpatient data from 1995. ${ }^{17}$ This registry includes information on civil registration number, dates of admission and discharge, surgical procedure(s) performed, and up to 20 diagnoses from each hospital contact. Since 1994, diagnoses have been classified according to the International Classification of Diseases 10th edition (ICD-10). The ICD codes used to identify breast cancer were ICD-10 C50.x.

\section{Survival}

Since 1968, the Central Office of Civil Registration has assigned a unique 10-digit personal identification number to all Danish citizens. ${ }^{18}$ This number, unique to each Danish resident, is used in all Danish registries, allowing unambiguous individual-level data linkage. From the Civil Registration System we also obtained information on vital status (dead or alive), date of death, and residence for all cancer patients.

\section{Statistical analysis}

We followed each patient from date of cancer diagnosis until emigration, death, or June 25, 2010, whichever came first. To visualize crude survival we constructed KaplanMeier curves, stratified according to period of diagnosis (1998-2000, 2001-2003, 2004-2006, and 2007-2009). We estimated 1-, 3-, and 5-year survival. In the latter periods we estimated 3- and 5-year survival using a hybrid analysis in which we included the actual survival for as long as possible and then estimated the conditional probability of surviving thereafter based on the corresponding survival experience of patients in the previous period (ie, using a period analysis technique). ${ }^{19}$ To compare all-cause mortality over time, we used Cox proportional hazard regression analysis, with 1998-2000 as the reference period to estimate 1-, 3-, and 5-year mortality rate ratios (MRRs) and corresponding 95\% confidence intervals (CIs), adjusting for age group (15-49 years, 50-74 years, and $>75$ years).

Analyses were performed using SAS (v 9.2; SAS Institute, Inc, Cary, NC).

\section{Results}

A total of 13,756 women had incident breast cancer during the period 1998-2009, with a median age of 62 years (range 21-102 years). The descriptive data are presented in Table 1 and Figure 1.

The annual number of women with incident breast cancer nearly doubled in the end of our study period, from a total of 962 in 1998 to 1758 in 2009. In 1998-2006, around 58\% of newly diagnosed breast cancer patients were in the age group 50-74 years. However, in 2007-2009, women aged 50-74 years constituted $70.1 \%$ of all newly diagnosed breast cancer patients (see Table 2). 


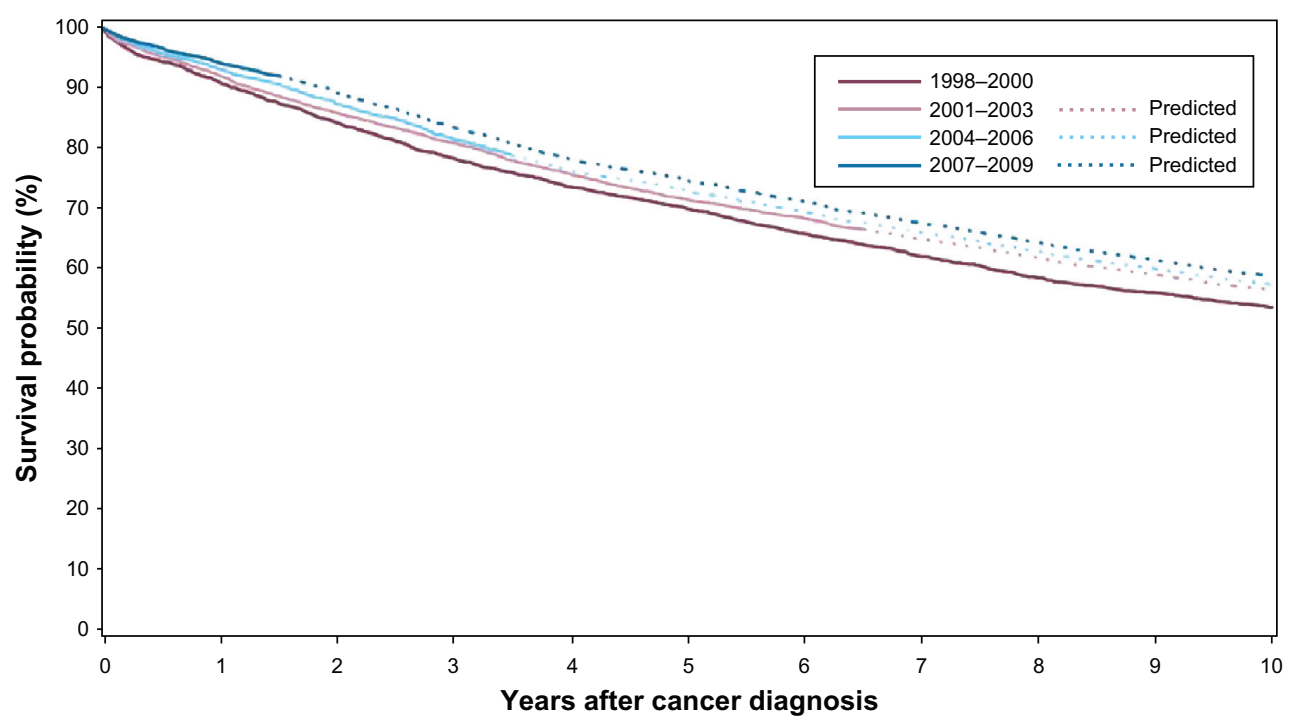

Figure I Survival curves for women with breast cancer, according to year of diagnosis, northern Denmark, 1998-2009.

The 1-year overall survival improved gradually from 90.9\% in 1998-2000 to $94.4 \%$ in 2007-2009 (Table 1 and Figure 1), corresponding to an unadjusted 1-year MRR of 0.61 (95\% CI: 0.51-0.73) in 2007-2009 compared with 1998-2000. After adjustment for age, the MRR was 0.68 (95\% CI: $0.56-0.79$ ). The 5-year survival was $70.0 \%$ in 1998-2000 and was predicted to be $74.7 \%$ in $2007-2009$. This yielded an adjusted 5-year MRR of 0.79 (95\% CI: 0.72-0.87) (Table 1 and Figure 1).

Among women aged 50-74 years, the 1-year survival increased from $92.8 \%$ in $1998-2000$ to $96.6 \%$ in $2007-2009$, and the 5-year predicted survival increased from $73.9 \%$ in $1998-2000$ to $80.2 \%$ in $2007-2009$ (Table 2). In women aged
15-49 years and more than 75 years both 1- and 5-year survival remained virtually unchanged during the study period; in the youngest women, the 1-year survivals were $97.0 \%-97.9 \%$, and 5-year survival/predicted survivals were $86.6 \%-87.6 \%$. In the elderly, the 1 -year survival was $81.3 \%-81.1 \%$, and 5 -year survival was $46.5 \%-45.9 \%$ (Table 2 ).

\section{Discussion}

In this population-based cohort study including nearly 14,000 breast cancer patients diagnosed between 1998 and 2009, we found that survival after breast cancer diagnosis gradually increased over the entire period. The 1-year mortality decreased more than $30 \%$, and the 5-year mortality was

Table I Cumulative survival and crude and adjusted MRRs, and associated $95 \%$ confidence intervals, for breast cancer patients diagnosed in northern Denmark, 1998-2009

\begin{tabular}{|c|c|c|c|c|}
\hline & \multicolumn{4}{|c|}{ Year of diagnosis } \\
\hline & $1998-2000$ & $200 I-2003$ & 2004-2006 & 2007-2009 \\
\hline Number of patients & 2996 & 3210 & 3126 & 4424 \\
\hline Median age (years) & 62 & 62 & 62 & 63 \\
\hline \multicolumn{5}{|l|}{ I year } \\
\hline Survival, \% & $90.9(89.8-91.9)$ & $92.0(91.0-92.9)$ & $93.2(92.2-94.0)$ & $94.4(93.6-95.0)$ \\
\hline MRR & I (reference) & $0.87(0.73-1.03)$ & $0.74(0.62-0.89)$ & $0.6 \mathrm{I}(0.5 \mathrm{I}-0.73)$ \\
\hline$M^{\prime} R^{a}$ & I (reference) & $0.89(0.75-1.06)$ & $0.74(0.62-0.89)$ & $0.68(0.57-0.81)$ \\
\hline \multicolumn{5}{|l|}{3 year } \\
\hline Survival, \% & $78.4(76.9-79.8)$ & $80.9(79.5-82.2)$ & $81.6(80.2-82.9)$ & $83.4(82.2-84.6)^{b}$ \\
\hline MRR & I (reference) & $0.87(0.78-0.97)$ & $0.83(0.74-0.93)$ & $0.73(0.65-0.8 \mathrm{I})^{\mathrm{b}}$ \\
\hline$M^{\prime} R^{a}$ & I (reference) & $0.89(0.80-0.99)$ & $0.83(0.74-0.93)$ & $0.77(0.68-0.85)^{\mathrm{b}}$ \\
\hline \multicolumn{5}{|l|}{5 year } \\
\hline Survival, \% & $70.0(68.4-71.6)$ & $71.5(69.9-73.0)$ & $73.0(71.4-74.5)^{\mathrm{b}}$ & $74.7(73.2-76.1)^{\mathrm{b}}$ \\
\hline MRR & I (reference) & $0.93(0.85-1.02)$ & $0.87(0.80-0.96)^{\mathrm{b}}$ & $0.79(0.72-0.87)^{\mathrm{b}}$ \\
\hline$M R^{a}$ & I (reference) & $0.96(0.87-1.05)$ & $0.88(0.80-0.96)^{b}$ & $0.82(0.75-0.90)^{\mathrm{b}}$ \\
\hline
\end{tabular}

Notes: aAdjusted for age; bpredicted values.

Abbreviation: MRR, mortality rate ratio. 
Table 2 Survival and associated 95\% confidence intervals in women with breast cancer, according to age and year of diagnosis for breast cancer patients diagnosed in northern Denmark, 1998-2009

\begin{tabular}{|c|c|c|c|c|}
\hline \multirow[t]{2}{*}{ Age (years) } & \multicolumn{4}{|c|}{ Year of diagnosis } \\
\hline & 1998-2000 & $200 \mathrm{I}-2003$ & 2004-2006 & 2007-2009 \\
\hline \multicolumn{5}{|l|}{$15-49$} \\
\hline Number of patients & $567(18.9 \%)$ & $636(19.8 \%)$ & $598(19.1 \%)$ & 615 (13.9\%) \\
\hline I-year survival, \% & $97.0(95.2-98.1)$ & 97.3 (95.7-98.3) & $98.2(96.7-99.0)$ & $97.9(96.3-98.8)$ \\
\hline 3-year survival, \% & $90.7(87.9-92.8)$ & $90.9(88.4-92.9)$ & $93.0(90.6-94.8)$ & $93.6(91.4-95.3)^{\mathrm{a}}$ \\
\hline 5-year survival, \% & $86.6(83.5-89.1)$ & $83.9(80.9-86.6)$ & $87.2(84.2-89.6)^{a}$ & $87.6(84.7-90.0)^{\mathrm{a}}$ \\
\hline \multicolumn{5}{|l|}{$50-74$} \\
\hline Number of patients & $1745(58.2)$ & 1875 (58.4\%) & I 826 (58.4\%) & 3102 (70.1\%) \\
\hline I-year survival, \% & $92.8(91.5-93.9)$ & $94.5(93.3-95.4)$ & 95.1 (94.0-96.0) & $96.6(95.9-97.2)$ \\
\hline 3-year survival, \% & $81.6(79.8-83.4)$ & $86.0(84.3-87.5)$ & $85.0(83.3-86.5)$ & $87.3(85.9-88.6)^{\mathrm{a}}$ \\
\hline 5-year survival, \% & $73.9(71.8-75.9)$ & $77.5(75.5-79.3)$ & $78.0(76.0-79.8)^{\mathrm{a}}$ & $80.2(78.4-81.9)^{\mathrm{a}}$ \\
\hline \multicolumn{5}{|l|}{$75+$} \\
\hline Number of patients & $684(22.8 \%)$ & $699(21.8 \%)$ & 702 (22.5\%) & 707 (16.0\%) \\
\hline I-year survival, \% & $81.1(78.0-83.9)$ & $80.7(77.6-83.4)$ & $83.8(80.8-86.3)$ & $81.3(78.2-84.1)$ \\
\hline 3-year survival, \% & $59.9(56.2-63.5)$ & $58.4(54.6-61.9)$ & $63.1(59.4-66.5)$ & $60.5(56.9-64.0)^{\mathrm{a}}$ \\
\hline 5-year survival, \% & $46.5(42.7-50.2)$ & $44.2(40.5-47.8)$ & $47.7(44.0-5 \mid .4)^{\mathrm{a}}$ & $45.9(42.2-49.5)^{\mathrm{a}}$ \\
\hline
\end{tabular}

Note: aPredicted values.

predicted to decrease by $20 \%$. In the end of our study period, however, the annual number of women diagnosed with breast cancer nearly doubled.

The main strength of our study is the population-based design with a well defined catchment area and virtually complete follow-up, which minimizes the potential for selection bias. The use of data from the DNRP allowed for analyses updated to recent calendar years; however, the codes from the DNRP may not be entirely accurate. A previous Danish study conducted in northern Denmark compared ovarian cancer diagnoses recorded in the DNRP with similar data from the Danish Cancer Registry. The completeness of ovarian cancer diagnoses in the DNRP was $96 \%$, and the positive predictive value was $87 \% .^{20}$ Thus, we cannot rule out some misclassification of our patients, and if the positive predictive value increased over the study period this may have influenced our estimates. However, we find it likely that women without a breast cancer diagnosis have a better survival than women with a breast cancer diagnosis. Therefore, we do expect improved predictive values to result in decreased survival. Our study has other limitations worth addressing. We do not have information on cancer stage, tumor size, hormone receptor status, choice of medical treatment, comorbidity, or lifestyle; all of which have an impact on breast cancer outcome..$^{12,21}$ Mortality trends among younger women with breast cancer could likely almost entirely be driven by breast cancer and its treatment, while mortality among older women is probably influenced by comorbidity. The improved survival among 50-74-year-old women in our study could thus to some extent be explained by improved survival in this age category in the general population. We are, however, unable to address the impact of these factors on the change we observed in breast cancer survival.

The weakness of the hybrid analysis design is that it may not be as accurate as directly observed survival. However, since we based our predictions on the survival experience in the previous period of our study, we expect our predictions to be conservative estimates of the increased survival among women with breast cancer.

Our finding of an improved breast cancer survival in central and northern Denmark extends the findings by Coleman et $\mathrm{al}^{3}$ based on data from the Danish Cancer Registry that relative 1- and 5-year survival improved during the period 1995-2007 and Mouridsen et al ${ }^{12}$ who based their study on data from the DBCG and similarly found an increased survival during the period 1977-2006. Mouridsen et al report an overall 5-year survival of $81 \%$ in 2002-2006, which is higher than the 5-year survival of $73 \%$ we found in 2004-2006. The DBCG is not entirely complete, as the registration earlier on of patients, who were not operated, was very limited, and this may explain differences in survival.

Several factors may explain the increase in survival that we observed. One possibility is changes in diagnostic procedures leading to earlier diagnosis. Breast cancer screening was introduced in our regions and offered to all women aged 50-69 years biennially in 2007 and $2008^{16}$ and may explain the nearly two-fold increase in the annual number of breast cancers in that period. If this increase in breast cancer incidence mainly occurred in tumors which were less aggressive than tumors detected outside screening programs, survival 
in the latest period may be affected by length time bias. ${ }^{22}$ Since the aim of screening is to detect cancers at an earlier stage ${ }^{16}$ survival will also be prolonged even without change in time of death (lead time bias). However, we also observed improvement in survival before the screening program was implemented. Thus other factors must be involved.

The technical quality of diagnostic imaging with digital mammography, high resolution ultrasound, stereotactic biopsies, and adjunct MRI mammography has improved over the years ${ }^{23-26}$ so cancers could be detected at an earlier stage, even before the introduction of the screening program.

However, the treatment of breast cancer in Denmark during our study period has changed towards treatment by specialized breast surgeons working in multidisciplinary teams in centralized units with a higher volume of patients than just a few years ago. ${ }^{27}$ This specialization might have contributed to the improved survival. ${ }^{9}$ More widespread use of standardized treatment following the DBCG protocols may also have had an important impact on the improved survival. ${ }^{12}$ These treatment changes include extended indications of adjuvant treatment with chemotherapy, endocrine treatment, biological treatment, and radiation therapy for smaller tumors, lower disease grades, and different age categories. ${ }^{8}$

In conclusion, survival among breast cancer patients has improved in Denmark over the time period 1998-2009, and this change was most pronounced in women aged 50-74 years. Introduction of a screening program in the last part of our study period might have contributed to these findings, but improvement of survival was also observed in the first part of our study period before the screening program was implemented. This could thus reflect changes in adjuvant treatment.

\section{Disclosure}

The authors report no conflicts of interest in this work.

\section{References}

1. Ferlay J, Shin HR, Bray F, Forman D, Mathers C, Parkin DM; for GLOBOCAN 2008. Cancer Incidence and Mortality Worldwide: IARC CancerBase No. 10 [Internet]. Lyon, France: International Agency for Research on Cancer; 2010. Available at: http://globocan.iarc.fr/ factsheets/cancers/breast.asp. Accessed February 23, 2011.

2. Tryggvadottir L, Gislum M, Bray F, et al. Trends in the survival of patients diagnosed with breast cancer in the Nordic countries 1964-2003 followed up to the end of 2006. Acta Oncol. 2010;49(5):624-631.

3. Coleman MP, Forman D, Bryant H, et al. Cancer survival in Australia, Canada, Denmark, Norway, Sweden, and the UK, 1995-2007 (the International Cancer Benchmarking Partnership): an analysis of populationbased cancer registry data. Lancet. 2011;377(9760):127-138.

4. Storm HH, Kejs AM, Engholm G, et al. Trends in the overall survival of cancer patients diagnosed 1964-2003 in the Nordic countries followed up to the end of 2006: the importance of case-mix. Acta Oncol. 2010; 49(5):713-724.
5. Andersen JS, Hansen SW. The cancer plan. Political will - professional formation. Ugesk Laeger. 2002;164(22):2885-2889. Danish.

6. Storm HH, Gislum M, Engholm G. Cancer survival before and after initiating the Danish Cancer Control plan. Ugesk Laeger. 2008;170(39):3065-3069. Danish.

7. Ahern TP, Larsson H, Garne JP, Cronin-Fenton DP, Sorensen HT, Lash TL. Trends in breast-conserving surgery in Denmark, 1982-2002. Eur J Epidemiol. 2008;23(2):109-114.

8. Møller S, Jensen MB, Ejlertsen B, et al. The clinical database and the treatment guidelines of the Danish Breast Cancer Cooperative Group (DBCG); its 30-years experience and future promise. Acta Oncol. 2008;47(4):506-524.

9. Skinner KA, Helsper JT, Deapen D, Ye W, Sposto R. Breast cancer: do specialists make a difference? Ann Surg Oncol. 2003;10(6):606-615.

10. Early Breast Cancer Trialists' Collaborative Group (EBCTCG). Effects of chemotherapy and hormonal therapy for early breast cancer on recurrence and 15-year survival: an overview of the randomised trials. Lancet. 2005;365(9472):1687-1717.

11. Clarke M, Collins R, Darby S, et al. Effects of radiotherapy and of differences in the extent of surgery for early breast cancer on local recurrence and 15-year survival: an overview of the randomised trials. Lancet. 2005;366(9503):2087-2106.

12. Mouridsen HT, Bjerre KD, Christiansen P, Jensen MB, Møller S. Improvement of prognosis in breast cancer in Denmark 1977-2006, based on the nationwide reporting to the DBCG Registry. Acta Oncol. 2008;47(4):525-536.

13. Olsen AH, Njor SH, Vejborg I, et al. Breast cancer mortality in Copenhagen after introduction of mammography screening: cohort study. $B M J$. 2005;330(7485):220.

14. Hellquist BN, Duffy SW, Abdsaleh S, et al. Effectiveness of populationbased service screening with mammography for women ages 40 to 49 years: evaluation of the Swedish Mammography Screening in Young Women (SCRY) cohort. Cancer. 2011;117(4):714-722.

15. Nystrom L, Andersson I, Bjurstam N, Frisell J, Nordenskjold B, Rutqvist LE. Long-term effects of mammography screening: updated overview of the Swedish randomised trials. Lancet. 2002;359(9310):909-919.

16. Christiansen P, Møller S, Bjerre KD. Kvalitetsindikatorrapport for brystkræft, 2009. 2010;1(1):5.

17. Andersen TF, Madsen M, Jorgensen J, Mellemkjoer L, Olsen JH. The Danish National Hospital Register. A valuable source of data for modern health sciences. Dan Med Bull. 1999;46(3):263-268.

18. Pedersen CB, Gotzsche H, Moller JO, Mortensen PB. The Danish Civil Registration System. A cohort of eight million persons. Dan Med Bull. 2006;53(4):441-449.

19. Brenner H, Rachet B. Hybrid analysis for up-to-date long-term survival rates in cancer registries with delayed recording of incident cases. Eur $J$ Cancer. 2004;40(16):2494-2501.

20. Tetsche MS, Norgaard M, Skriver MV, Andersen ES, Lash TL, Sorensen HT. Accuracy of ovarian cancer ICD-10 diagnosis in a Danish population-based hospital discharge registry. Eur J Gynaecol Oncol. 2005;26(3):266-270.

21. Patterson RE, Cadmus LA, Emond JA, Pierce JP. Physical activity, diet, adiposity and female breast cancer prognosis: a review of the epidemiologic literature. Maturitas. 2010;66(1):5-15.

22. Autier P, Boniol M. Caution needed for country-specific cancer survival Lancet. 2011;377(9760):99-101.

23. Schueller G, Riedl CC, Mallek R, et al. Image quality, lesion detection, and diagnostic efficacy in digital mammography: full-field digital mammography versus computed radiography-based mammography using digital storage phosphor plates. Eur J Radiol. 2008;67(3):487-496.

24. Skaane P. Studies comparing screen-film mammography and full-field digital mammography in breast cancer screening: updated review. Acta Radiol. 2009;50(1):3-14.

25. Utzon-Frank N, Vejborg I, von Euler-Chelpin M, Lynge E. Balancing sensitivity and specificity: Sixteen year's of experience from the mammography screening programme in Copenhagen, Denmark. Cancer Epidemiol. January 14, 2011. [Epub ahead of print]. 
26. Moy L, Elias K, Patel V, et al. Is breast MRI helpful in the evaluation of inconclusive mammographic findings? Am J Roentgenol. 2009;193(4):986-993.
27. Kroman N, Christiansen P, Hussain ZB, Kehlet H. Breast cancer surgery in Denmark. Ugeskr Laeger. 2010;172(41):2836-2839. Danish.

\section{Publish your work in this journal}

Clinical Epidemiology is an international, peer-reviewed, open access journal focusing on disease and drug epidemiology, identification of risk factors and screening procedures to develop optimal preventative initiatives and programs. Specific topics include: diagnosis, prognosis, treatment, screening, prevention, risk factor modification, systematic

Submit your manuscript here: http://www.dovepress.com/clinical-epidemiology-journal reviews, risk \& safety of medical interventions, epidemiology \& biostatical methods, evaluation of guidelines, translational medicine, health policies \& economic evaluations. The manuscript management system is completely online and includes a very quick and fair peer-review system, which is all easy to use. 